\title{
Equilibrium Strategies of Manufacturer's Encroachment under a Capital-Constraint Retailer
}

\author{
Zhen Wu, Gengjun Gao \\ Institute of Logistics Science and Engineering Research, Shanghai Maritime University, Shanghai, China \\ Email: wuzhen6526@163.com
}

How to cite this paper: $\mathrm{Wu}, \mathrm{Z}$., \& Gao, G. J. (2020). Equilibrium Strategies of Manufacturer's Encroachment under a Capital-Constraint Retailer. Open Journal of Business and Management, 8, 2633-2648.

https://doi.org/10.4236/ojbm.2020.86163

Received: September 13, 2020

Accepted: November 17, 2020

Published: November 20, 2020

Copyright $\odot 2020$ by author(s) and Scientific Research Publishing Inc. This work is licensed under the Creative Commons Attribution International License (CC BY 4.0).

http://creativecommons.org/licenses/by/4.0/

\begin{abstract}
In this paper, we investigate a two-echelon supply chain consisting of a manufacturer and a capital-constraint retailer. Based on this supply chain, the manufacturer, as the leader in the Stackelberg game, decides whether to channel encroachment, and the retailer, as the follower, decides which financing mode to adopt. Based on Stackelberg game, we established the corresponding game models to obtain the equilibriums. The research results show that the manufacturer's channel encroachment is related to the channel establishing cost. When the channel encroachment cost is small, the manufacturer opens direct channel. Conversely, manufacturers do not build direct channels. After the encroachment, the manufacturer chose to sell products through dual channels. The equilibrium of single channel financing is internal financing. In the case of dual channels, the retailer's financing decision is related to the equity financing ratio, which is relatively small, and external financing is financing equilibrium.
\end{abstract}

\section{Keywords}

Manufacturer Encroachment, Financing Strategies, Stackelberg Game, Supply Chain Management

\section{Introduction}

The rapid development of e-commerce has become a new engine for online direct sales. In 2018, national online retail sales reached 5.3 trillion yuan, a year-on-year increase of 34.2\% (Duan \& Jiao, 2019). More and more upstream manufacturers, such as Huawei, Apple, Nike, etc, have established direct sales channels on the basis of traditional retail channels, forming a dual-channel 
model to sell products to increase market share (Li et al., 2014a, Xia \& Niu, 2019). In this case, manufacturers and retailers not only cooperate vertically, but also produce "channel conflict".

With increasing market competition, capital constraints have become a common problem faced by enterprises, especially small and medium-sized enterprises. When retailers lack funds, they cannot make optimal decisions due to funding problems, which will affect the payoff of supply chain members. Therefore, the establishment of diversified corporate financing channels, enabling companies to carry out effective financing is conducive to the development of the supply chain. At present, financing strategies are mainly divided into two types according to the source of funds: internal financing and external financing. Internal financing is the inter-upstream and downstream financing of the supply chain (trade credit) (Chen, 2015). For example, in the United Kingdom, 80\% of B2B transactions are conducted through trade credit (Daniel et al., 2013); external financing means borrowing from external financial institutions to raise money (bank loans, equity financing, etc.) (Wang et al., 2019).

Dual-channel supply chain has become a hot topic. Many scholars have studied the decision of manufacturer encroachment under different influencing factors and achieved a series of results. Li et al. (2014b) studied that under asymmetric information, supplier intrusion not only causes a win-win situation for suppliers and retailers, but also may result in loss of one party, profit of one party, or loss of both parties. Yoon (2016) studies that when manufacturers invade the retail channel, the production efficiency of the direct channel is improved by reducing cost investment, and retailers also benefit from the spillover effect of manufacturers' investment. Fan and Liu (2016) studied that after the encroachment of manufacturers, the higher the suitability of direct channel products is, the more favorable it is to encourage retailers to improve product service quality, and finally the manufacturers and retailers can achieve a win-win result. Yang et al. (2018) studied the impact of nonlinear pricing on supplier encroachment, and the results showed that nonlinear pricing and revenue sharing could coordinate supply chain revenue.

Most scholars consider the financing decisions of supply chain members from the perspectives of internal and external financing, and study the influence of different factors on supply chain financing decisions.

The research of Peura et al. (2017) shows that trade credit can ease the horizontal competition between suppliers. Wang et al. (2019) studied the equilibrium decision of online retailers' financing in EB platform and bank financing. Through the equilibrium and coordination analysis, the results showed that EB platform financing can realize the coordination of supply chain financing and generate more income than bank financing. Li et al. (2019) studied a dual-channel supply chain consisting of a supplier and a manufacturer with capital constraints, both of which cooperate and compete. According to their preference structure of trade credit, bank loan and bank equity hybrid financing, they analyzed and 
concluded that trade credit and hybrid financing are financing equilibrium. Yang et al. (2017) studied a two-echelon supply chain consisting of one supplier and two capital-constrained retailers, and the competition among retailers was Gournot, and analyzed the impact of equity financing ratio on the financing decisions of retailers. In addition, Xiao and Luo (2016) studied the retailer's trade credit financing model and bank loan financing model with price discounts under decentralized decision-making and centralized decision-making and found that the manufacturer's best financing decision is related to its initial funding level. Zhang and Wang (2014) investigated the deferred payment model and loan payment model are respectively analyzed by Stackelberg game theory according to different ways of solving the problem of insufficient funds of retailers, and proved that the retailer chooses the deferred payment model as its optimal decision.

In the existing literature, there are more studies on the influence of different factors on the encroachment of manufacturers, less studies on the strategy of channel encroachment of manufacturers when there are financial constraints on the retailer, less on the model analysis of direct channel introduction, and less on the integrity of channel structure. In addition, the existing literature mainly studies the financing decisions of the retailer on different financing strategies, and seldom studies the influence of manufacturers' channel choice and channel encroachment on the financing strategies of the retailer. In this paper, we study the problems neglected in the above literature, and consider two-echelon supply chain consisting of a manufacturer and a retailer, which has financial constraints. Based on this supply chain manufacturer whether to invade, and the channel selection after the invasion. According to the manufacturer's channel decision, the retailer chooses the financing strategies. Financing strategies can be divided into internal financing and external financing according to capital sources. Internal financing is trade credit. External financing is a mixture of bank and equity financing.

\section{Problem Description and Assumptions}

As mentioned, this paper considers a supply chain which consists of a manufacturer and a capital-constraint retailer. The manufacturer, as the leader of Stackelberg game in the supply chain, decides whether to invade the retail channel and establish the network direct channel. As the follower of Stackelberg game, the retailer with capital constraint decides which financing strategy to adopt according to the manufacturer's encroachment strategies. Then, the manufacturer decides the wholesale price according to its own revenue maximization, the retailer decides the optimal retail channel order quantity based on the wholesale price given by the manufacturer, and finally the manufacturer decides the optimal direct channel order quantity (encroachment) (Matsui, 2017). The decision-making sequence of events is shown in Figure 1: 


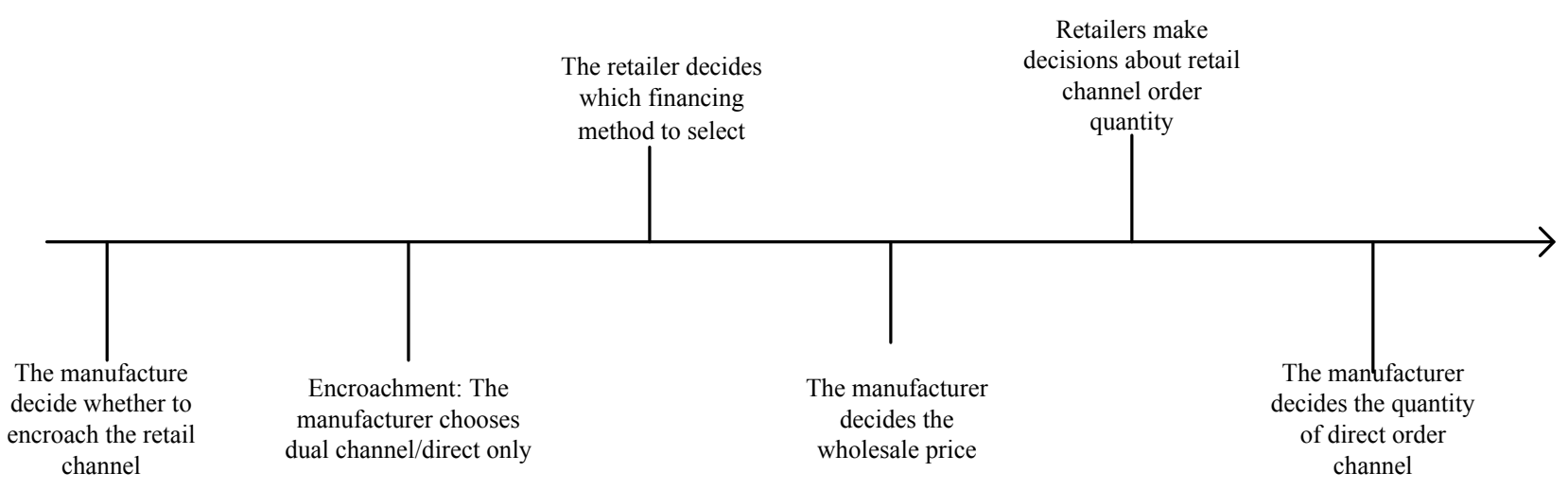

Figure 1. The sequence of events.

Assume that supply chain members face a deterministic demand market, and the market demand is. To simplify the model, it is assumed that the production cost of the manufacturer is 0 (Guo et al., 2017a, 2017b) and the initial capital of the retailer is 0 (Yan et al., 2019). In the absence of channel encroachment by the manufacturer, The manufacturer charges a wholesale price $w_{n}$ for each unit of product from the retailer, then the retailer sells to the customers at retail price $p_{r, n}$. Specially, the demand function can be described as follows: $p_{r, n}^{k}=a-q_{r, n}^{k}$, where $a$ is the market size. If the manufacturer encroaches the retail channel, the retailer will face quantity competition from the manufacturer. We assume the demand function as $p_{i, e}^{k}=a-q_{i, e}^{k}-d q_{j, e}^{k}$, where $e$ represents the manufacturer decides to encroach, and $i, j \in\{r, m\} \quad$ (retail channel $r$ and direct channel $m$ ), $d$ is the quantity competition coefficient between the two channels. The Variable definitions of the model are shown in Table 1.

\section{The Model}

\subsection{The Model for Supply Chain Members under Retail Channel Only}

When the manufacturer does not encroach the traditional retail channels, the retailer alleviates the shortage of funds by means of internal or external financing, and the retailer determines the financing strategies by comparing the optimal returns under different financing strategies.

\subsubsection{Internal Financing}

The retailer has financial constraints and cannot make optimal order decisions, which will result in the order loss of upstream manufacturers to some extent. In the same time, upstream manufacturers provide trade credit and charge certain interest rate $r_{m}$ on loans. At the beginning of the sales period, the retailer does not have to make payment to the manufacturer. At the end of the sales period, the retailer pays $w q_{r, n}^{T} r_{m}$ to the manufacturer. The manufacturer gets $w q_{r, n}^{T}\left(1+r_{m}\right)$ from the retail channel. Expected Payoff of the retailer and the manufacturer can be calculated as follows: 
Table 1. Variable definitions.

\begin{tabular}{cc}
\hline Notation & Definition \\
\hline$a$ & Market demand \\
$d$ & Quantity competition coefficient between the two channels $d \in[0,1]$ \\
$r_{m}$ & Equity financing ratio $\phi \in[0,1]$ \\
$r_{f}$ & Interest rate of trade credit $r_{m} \in(0,1)$ \\
$p_{r, y}^{k}$ & Bank loans rate/risk-free rate $r_{f} \in(0,1)$ \\
$q_{r, y}^{k}$ & The order quantity of the retailer under $y$ scenario under $k$ financing strategy \\
$\pi_{r, y}^{k}$ & Expected payoff of the retailer under $y$ scenario under $k$ financing strategy \\
$\pi_{m, y}^{k}$ & Expected payoff of the manufacture under $y$ scenario under $k$ financing strategy \\
\hline & $\left\{\begin{array}{l}\pi_{r, n}^{T}=p_{r, n}^{T} q_{r, n}^{T}-w^{T} q_{r, n}^{T}\left(1+r_{m}\right) \\
\pi_{m, n}^{T}=w^{T} q_{r, n}^{T}\left(1+r_{m}\right)\end{array}\right.$
\end{tabular}

Here, $p_{r, n}^{T}=a-q_{r, n}^{T}$.

So let's substitute $p_{r, n}^{T}=a-q_{r, n}^{T}$ into $\pi_{r, n}^{T}$, moreover, let $\partial \pi_{r, n}^{T} / \partial q_{r, n}^{T}=0$, solve the equation to get the order quantity of the retailer: $q_{r, n}^{T}=\left[a-w_{n}^{T}\left(1+r_{m}\right)\right] / 2$, Substitute this formula into the manufacturer's payoff $\pi_{m, n}^{T}$, afterwards, let $\partial \pi_{m, n}^{T} / \partial w_{n}^{T}=0$, we can obtain the manufacturer's optimal wholesale price:

$$
w_{n}^{T^{*}}=a / 2\left(1+r_{m}\right)
$$

Substitute $w_{n}^{T^{*}}$ into $q_{r, n}^{T}$, we can derive the optimal order quantity:

$$
q_{r, n}^{T^{*}}=a / 4
$$

The optimal expected payoff of the retailer and the manufacture are as follows:

$$
\left\{\begin{array}{l}
\pi_{r, n}^{T^{*}}=a^{2} / 16 \\
\pi_{m, n}^{T^{*}}=a^{2} / 8
\end{array}\right.
$$

Corollary 1: $\frac{\partial w_{n}^{T^{*}}}{\partial r_{m}}<0 ; \frac{\partial q_{r, n}^{T^{*}}}{\partial r_{m}}=0 ;$

The wholesale price of internal financing is negatively correlated with the trade credit ratio, because the higher the trade credit ratio is, the higher the loan cost will be paid by the retailer, which will reduce the enthusiasm of the retailer to order. In order to motivate the retailer, the manufacturer compensates the retailer from the perspective of wholesale price. Retail channel demand has nothing to do with trade credit interest rate.

\subsubsection{External Financing}

The retailer adopts external financing to satisfy their capital needs, namely: equity financing and bank financing. Suppose that the equity financing ratio is $\phi$, 
and the remainder $1-\phi$ is bank loans. At the beginning of the sales period, the retailer pays the full payment on goods to the manufacturer, who invests the money into the market and is rewarded at a risk-free rate $r_{f}$. At the final stage of the sale, the retailer repays the bank $(1-\phi) w_{n}^{E} q_{r, n}^{E}\left(1+r_{f}\right)$ at the bank loan rate $r_{f}$, which is equal to the risk-free rate. $\pi_{r, n}^{E}$ and $\pi_{m, n}^{E}$ denote the expected payoff of the retailer and the manufacturer in this scenario:

$$
\left\{\begin{array}{l}
\pi_{r, n}^{E}=(1-\phi)\left[p_{r, n}^{E} q_{r, n}^{E}-(1-\phi) w_{n}^{E} q_{r, n}^{E}\left(1+r_{f}\right)\right] \\
\pi_{m, n}^{E}=w_{n}^{E} q_{r, n}^{E}\left(1+r_{f}\right)
\end{array}\right.
$$

According to the game idea of 3.1.1, the manufacturer's optimal wholesale price can be solved:

$$
w_{n}^{E^{*}}=a /\left[2\left(1+r_{f}\right)(1-\phi)\right]
$$

The optimal order quantity of the retailer can be obtained:

$$
q_{r, n}^{E^{*}}=a / 4
$$

The optimal expected payoff of the retailer and the manufacture are as follows:

$$
\left\{\begin{array}{l}
\pi_{r, n}^{E^{*}}=\left[a^{2}(1-\phi)\right] / 16 \\
\pi_{m, n}^{E^{*}}=a^{2} /[8(1-\phi)]
\end{array}\right.
$$

Corollary 2: $\frac{\partial w_{n}^{E^{*}}}{\partial \phi}>0 ; \frac{\partial q_{r, n}^{E^{*}}}{\partial \phi}=0$;

The higher the equity financing ratio is, the lower the bank financing ratio is, and the lower the interest paid by the retailer will be. However, in the retail channel only, the order quantity of the retailer will remain the constant, so the manufacturer will raise the wholesale price to obtain more income. When the manufacturer does not encroach the channel, from this formula $q_{r, n}^{E^{*}}=q_{r, n}^{T^{*}}=a / 4$, we know that the demand is not affected by the financing strategies.

\subsection{The Model under Direct Channel Only}

When there is only a direct channel, the manufacturer gains only from the direct channel. The cost for the manufacturer to establish direct channels is $F$, considering the risk-free interest rate, so the manufacturer's expected payoff is:

$$
\pi_{m}=p_{m} q_{m}-F\left(1+r_{f}\right)
$$

Here, $q_{m}=a-p_{m}$.

Substitute $q_{m}=a-p_{m}$ into $\pi_{m}$, let $\partial \pi_{m} / \partial q_{m}=0$, we can derive the optimal order quantity:

$$
q_{m}^{*}=a / 2
$$

The manufacturer's optimal payoff can be represented as follows:

$$
\pi_{m}^{*}=a^{2} / 4-F\left(1+r_{f}\right)
$$




\subsection{The Model of Supply Chain under Two Channels}

Internal Financing

If the manufacturer chooses to encroach the retail channel, simultaneously, the retailer chooses the internal financing. In this scenario, after the retailer obtains the income at the end of the sales period, it is required to repay the financing principal and interest $w_{e}^{T} q_{r, e}^{T}\left(1+r_{m}\right)$ for the manufacturer. With regard to the manufacture, after establishing the direct channel, if can get benefits from both retail channel and direct channel. In addition, considering the risk-free interest rate, the cost for manufacturers to develop direct channels is denoting $F\left(1+r_{f}\right) \cdot \pi_{r, e}^{T}$ and $\pi_{m, e}^{T}$ represent expected payoff of the retailer and manufacturer under this scenario:

$$
\left\{\begin{array}{l}
\pi_{r, e}^{T}=p_{r, e}^{T} q_{r, e}^{T}-w_{e}^{T} q_{r, e}^{T}\left(1+r_{m}\right) \\
\pi_{m, e}^{T}=w_{e}^{T} q_{r, e}^{T}\left(1+r_{m}\right)+p_{m, e}^{T} q_{m, e}^{T}-F\left(1+r_{f}\right)
\end{array}\right.
$$

Here, $p_{r, e}^{T}=a-q_{r, e}^{T}-d q_{m, e}^{T}, \quad p_{m, e}^{T}=a-q_{m, e}^{T}-d q_{r, e}^{T}$.

Take the first derivative of the manufacturer's payoff with respect to $q_{m, e}^{T}$ and set it to 0 , that is $\partial \pi_{m, e}^{T} / \partial q_{m, e}^{T}=0$, then we can get the optimal order quantity $q_{m, e}^{T}=\left(a-d q_{r, e}^{T}\right) / 2$ of direct channel. Furthermore, put this formula in $\pi_{m, e}^{T}$, and get the manufacturer's optimal wholesale price according to the game idea of 3.1.1:

$$
w_{e}^{T^{*}}=a\left[8-d^{2}(6-d)\right] /\left[2\left(8-5 d^{2}\right)\left(1+r_{m}\right)\right]
$$

The optimal order quantity of two channels:

$$
\left\{\begin{array}{l}
q_{r, e}^{T^{*}}=2 a(1-d) /\left(8-5 d^{2}\right) \\
q_{m, e}^{T^{*}}=[a(2+d)(4-3 d)] / 2\left(8-5 d^{2}\right)
\end{array}\right.
$$

The manufacturer's optimal payoff can be represented as follows:

$$
\left\{\begin{array}{l}
\pi_{r, e}^{T^{*}}=2 a^{2}(1-d)^{2}\left(2-d^{2}\right) /\left(8-5 d^{2}\right)^{2} \\
\pi_{m, e}^{T^{*}}=a^{2}[12-d(8+d)] / 4\left(8-5 d^{2}\right)-F\left(1+r_{f}\right)
\end{array}\right.
$$

Corollary 3: $\frac{\partial \pi_{r, e}^{T^{*}}}{\partial d}<0 ; \quad \frac{\partial \pi_{m, e}^{T^{*}}}{\partial d}<0$;

The Corollary 3 illustrates that competition between channels damages the profits of supply chain members. Thus, when channel competition intensifies, the retailer will seek for new development direction, so the order quantity from manufacturers will decrease, which will affect the manufacturers' market share and reduce the expected earnings of both sides.

\section{Retailer Financing Equilibrium}

In this paper, the manufacturer initially decides whether to conduct channel encroachment, and the retailer makes financing decisions according to the manufacturer's invasion strategies and maximizes the expected revenue. According to 
the game theory to solve the inverse analysis method, the retailer financing equilibrium is discussed firstly, and the manufacturer encroachment equilibrium strategies are discussed based on the retailer financing equilibrium.

\subsection{The Sub Equilibrium of Retailer Financing under Single Channel}

When the manufacturer does not carry out channel encroachment, at this point, only traditional retail channels exist in the market, and the retailer chooses the financing modes according to the maximum expected payoff.

Lemma 1: In the absent of the encroachment, the retailer will choose internal financing as their financing strategy for equity financing ratio $\phi \in(0,1)$.

Proof of Lemma 1: When the retailer chooses internal financing strategy, the maximum expected payoff is $\pi_{r, n}^{T^{*}}=a^{2} / 16$, while when the retailer adopts external financing strategy, the maximum expected return is $\pi_{r, n}^{E}=a^{2}(1-\phi) / 16$, and the range of $\phi$ is $(0,1)$, accordingly, $\pi_{r, n}^{T^{*}}>\pi_{r, n}^{E^{*}}$ is always true. In the meanwhile, it can be concluded that the financing decisions of the retailer are only related to the equity financing ratio.

According to Lemma 1 , if the equity financing ratio is greater than 0 , the internal financing is the retailer financing equilibrium. When the manufacturer does not encroach the retail channel, the manufacturer and the retailer do not have a competitive relationship. On the contrary, they are a community of shared interests, while the external financing will cause the third party to earn profits and reduce the total income. Briefly, internal financing refers to the circulation of funds within the supply chain, so internal financing is the financing equilibrium of the retailer.

\subsection{The Sub Equilibrium of Retailer Financing under Dual Channel}

When the manufacturer encroaches into the retail channel, which financing strategy the retailer adopts, the threshold value of financing strategies selection is calculated by comparing the change of the manufacturer's income with that of internal financing and external financing.

Lemma 2: When the manufacturer decides to encroach the retail channel, when $\phi$ satisfies the condition $\phi \in\left(0, \phi_{e}\right)$, the retailer adopts external financing. Otherwise, the retailer chooses internal financing as the financing strategy.

Proof of Lemma 2: Compare the payoff of the retailer when she chooses different strategies of internal financing and external financing. let $\Delta \pi_{r, e}^{E^{*}-T^{*}}$ denotes the increment of the retailer's income, and then there is $\Delta \pi_{r, e}^{T^{*}-E^{*}}=\pi_{r, e}^{T^{*}}-\pi_{r, e}^{E^{*}}$. Considering the non-negative equity financing ratio, when $\phi \in\left(0, \phi_{e}\right)$, the results $\pi_{r, e}^{T}<\pi_{r, e}^{E}$ appears. As a consequence, the retailer chooses external financing; Conversely, $\pi_{r, e}^{T}>\pi_{r, e}^{E}$, the retailer chooses internal financing. At this point,

$$
\phi_{e}=\left\{A(2+d)(4-3 d)-256 d+320 d^{2}+320 d^{3}-d^{4}[404+d(92-121 d)]\right\} / 2 d^{2}\left(8-5 d^{2}\right)^{2} \text {, }
$$


among which

$$
A=\sqrt{d^{3}\left\{512-448 d-608 d^{2}+d^{3}[532+d(172-151 d)]\right\}} .
$$

From $\partial \pi_{r, e}^{E^{*}} / \partial \phi<0$ known that retailer's income is negatively correlated with equity financing ratio. In other words, with the increase of the proportion of equity financing, the loan interest paid by the retailer decreases, and the profit loss of the retailer due to the manufacturer's increased wholesale price is higher than the income increment of the retailer due to the reduction of the bank loan ratio. In addition, according to (14) and (18), $q_{r, e}^{T^{*}}+q_{m, e}^{T^{*}}<q_{r, e}^{E^{*}}+q_{m, e}^{E^{*}}$, that is, when the retailer chooses internal financing, the optimal total order of dual-channel is lower than the optimal total order of external financing. Therefore, when the retailer chooses external financing, it is conducive to the manufacturer's market expansion and attracts more customers.

\subsection{The Equilibrium of Retailer Financing}

According to lemma 1 and Lemma 2, the total equilibrium of retailer financing is obtained. See Theorem 1

Theorem 1: Regardless of whether the manufacturer chooses a channel encroachment strategy, the retailer will choose the financing strategy that maximizes its expected revenue. $\phi \in\left(0, \phi_{e}\right)$, in the case of single channel, the retailer chooses internal financing, while in the case of double channel, the retailer chooses external financing; $\phi \in\left(\phi_{e}, 1\right)$, the single-channel retailer chooses internal financing, while the dual-channel the retailer chooses internal financing.

\section{External Financing}

If the manufacturer chooses to encroach the retail channel, in the meanwhile, the retailer adopts external financing (Banks, equity financing). Under this circumstance, assuming that the ratio of equity financing is $\phi$, the ratio of bank financing is $1-\phi$, the retailer gets funds $\phi w_{e}^{E} q_{r, e}^{E}$ through equity financing, besides, the retailer gets funds $\phi w_{e}^{E} q_{r, e}^{E}$ through bank loans. At the beginning of the sales period, the retailer delivers the full payment from the financing to the manufacturer, who returns the funds to the market at a risk-free rate. Moreover, at the end of the selling period, the retailer will have to repay its earnings to investors at a ratio $\phi$ and the bank's principal and interest at an interest rate $r_{f}$. In addition, considering the risk-free interest rate, it requires costs $F\left(1+r_{f}\right)$ to develop direct channels. Therefore, the expected payoff of the retailer and the manufacturer under the situation are as follows:

$$
\left\{\begin{array}{l}
\pi_{r, e}^{E}=(1-\phi)\left[p_{r, e}^{E} q_{r, e}^{E}-(1-\phi) w_{e}^{E} q_{r, e}^{E}\left(1+r_{f}\right)\right] \\
\pi_{m, e}^{E}=w_{e}^{E} q_{r, e}^{E}\left(1+r_{f}\right)+p_{m, e}^{E} q_{m, e}^{E}-F\left(1+r_{f}\right)
\end{array}\right.
$$

Take the first derivative of the manufacturer's payoff with respect to $q_{m, e}^{E}$ and set it to 0 , that is $\partial \pi_{m, e}^{E} / \partial q_{m, e}^{E}=0$. From this equation we can derive the optimal order quantity $q_{m, e}^{T}=\left(a-d q_{r, e}^{T}\right) / 2$ of direct channel. So substitute this 
into $\pi_{m, e}^{T}$,

According to the game idea of 3.1.1, the manufacturer's optimal wholesale price is obtained:

$$
w_{e}^{E^{*}}=\{8 a+a d\{d[(2+d) \phi+d-6]-4 \phi\}\} / 2\left(1+r_{f}\right)(1-\phi)\left[8-d^{2}(5-\phi)\right](17)
$$

The optimal order quantity of two channels:

$$
\left\{\begin{array}{l}
q_{r, e}^{E^{*}}=a[2-d(2-\phi)] /\left[8-d^{2}(5-\phi)\right] \\
q_{m, e}^{E^{*}}=a(2+d)(4-3 d) / 2\left[8-d^{2}(5-\phi)\right]
\end{array}\right.
$$

The manufacturer's optimal payoff can be represented as follows:

$$
\begin{aligned}
& \left\{\begin{array}{l}
\pi_{r, e}^{E^{*}}=a^{2}\left(2-d^{2}\right)(1-\phi)[2-d(2-\phi)]^{2} / 2\left[8-d^{2}(5-\phi)\right]^{2} \\
\pi_{m, e}^{E^{*}}=a^{2}\{12-8 \phi-d[8+d-2 \phi(2+d)]\} / 4(1-\phi)\left[8-d^{2}(5-\phi)\right]-F\left(1+r_{f}\right)
\end{array}\right. \\
& \text { Corollary 4: } \frac{\partial q_{r, e}^{E^{*}}}{\partial \phi}>0 ; \frac{\partial q_{m, e}^{E^{*}}}{\partial \phi}>0 ; \frac{\partial w_{e}^{E^{*}}}{\partial \phi}>0 ; \frac{\partial \pi_{m, e}^{E^{*}}}{\partial \phi}>0 ;
\end{aligned}
$$

The higher the equity financing ratio is, the lower the bank loan ratio will be, and the less the financing interest will be paid by the retailer. Therefore, the retailer will increase their order quantity, while the manufacturers need to reduce the order quantity from direct channel. However, in order to make up for the decrease of the direct channel revenue, the manufacturer raised the wholesale price of the retail channel; The payoff of the manufacturer are in direct proportion to the equity financing ratio, which indicates that the profit margin obtained by the manufacturer rom retail channels is higher than that lost by direct channels and compensates for the losses.

\section{Manufacturer Channel Encroachment Decisions}

\subsection{Manufacturer Channel Selection}

Based on the general equilibrium of the retailer financing in Theorem 1, under the premise that the manufacturer chooses to establish direct channel, we studied whether the manufacture chooses to sell products only through direct channels, or whether direct sales and retail channels constitute dual-channel sales of products. Channel selection strategies are obtained by comparing the payoff of the manufacturer in the direct-channel scenario with the payoff of the manufacturer in the dual-channel sales scenario.

Lemma 2: In the case of direct channel established, the manufacturer chooses double channel as its own channel strategies.

Proof of Lemma 2: Let the variation of manufacturer's revenue in direct selling and dual-channel only be $\Delta \pi_{m, e}$, and when $\phi \in\left(0, \phi_{e}\right)$, it can be obtained that $\Delta \pi_{m}=\pi_{m, e}^{E^{*}}-\pi_{m}^{*}>0$ is constant, that is, the profit of manufacturer in dual-channel is higher than that in direct selling only. When $\phi \in\left(\phi_{e}, 1\right)$, it can be obtained that $\Delta \pi_{m}=\pi_{m, e}^{E^{*}}-\pi_{m}^{*}>0$ is constant, that is, the profit of manufacturer under dual channels is higher than that of direct sales only. It is con- 
cluded that manufacturers always choose dual channels to sell their products in the context of developing direct channels.

By selling only through the direct channel, the manufacturer will lose out to consumers who prefer the retail channel. If a manufacturer chooses to sell products through two channels, it can gain revenue from both channels. A dual channel with complementary sales methods will increase the market share of products and increase the overall revenue of the manufacturer.

\subsection{The Equilibrium of Encroachment Decisions}

According to Lemma 3, when making channel selection decisions, the manufacturer always chooses to sell products through dual channels. What's more, once the manufacturer decides to choose to encroach the retail channel, it is necessary to consider the cost of the channel establishment and the possible profits of the direct channel. Meanwhile, the impact of the competition between the direct channel and the retail channel on the market is unknown. Hence, whether the manufacturer will encroach the direct channel can be obtained by comparing the profit of the manufacturer under the single channel scenario and the profit under the double channel scenario. See Lemma 4:

Theorem 2: $\phi \in\left(0, \phi_{e}\right)$, when is satisfied, the manufacturer chooses to establish the direct channel; otherwise, it will not develop the direct channel; $\phi \in\left(\phi_{e}, 1\right)$, and when $F \in\left(0, F^{T-T}\right)$, the manufacturer chooses to develop the direct channel, otherwise does not establish the channel.

Proof of Theorem 2: Let $\Delta \pi_{m-e}$ denotes the manufacturer's revenue variation before and after channel being established. If $\phi \in\left(0, \phi_{e}\right)$, then $\Delta \pi_{m-e}^{T^{*}-E^{*}}=\pi_{m}^{T^{*}}-\pi_{m, e}^{E^{*}}$, and we can derive that $F \in\left(0, F^{T-E}\right)$, the manufacturer chooses to build the direct sales channel; On the contrary, he won't do that, here $F^{T-T}=a^{2}[40-(32-d) d] / 16\left(1+r_{f}\right)\left(8-5 d^{2}\right)$. If $\phi \in\left(\phi_{e}, 1\right)$, then $\Delta \pi_{m-e}^{T^{*}-T^{*}}=\pi_{m}^{T^{*}}-\pi_{m, e}^{T^{*}}$, we can obtain $F \in\left(0, F^{T-T}\right)$, the manufacture decides to establish the direct channel. Conversely, he won't do that, in which $F^{T-E}=a^{2}\left[40-16 d(2-\phi)-24 \phi+d^{2}(1+\phi)^{2}\right] / 16\left(1+r_{f}\right)\left[8-d^{2}(5-\phi)\right](1-\phi)$.

It is known from theorem 2 that the manufacturer will establish direct channel only when the revenue from two channels is higher than that from single channel, that is, when the cost of establishing direct channel is lower than the revenue after the encroachment. Obviously, the establishment of the direct channel within the threshold of channel cost will bring more benefits to the manufacturer.

\section{Numerical Simulation}

In this section, the channel encroachment decision of the manufacturer and the financing decision of the retailer is simulated and analyzed through numerical examples. The following model parameters are assumed: the market demand $a=10$, channel competition coefficient $d=0.7$. 
Figure 2(a) and Figure 2(b) intuitively reflect the relationship between channel building decision and channel encroachment cost. Figure 2(a) shows that when $F \in\left(0, F^{T-E}\right), \pi_{m, e}^{T^{*}}>\pi_{m}^{T^{*}}$ that is the cost is usually lower, and the more the manufacturer is willing to build direct channels. Simultaneously, the analysis of Figure 2(b) is similar to Figure 2(a). Furthermore, the two figures confirm the accuracy of theorem (2).

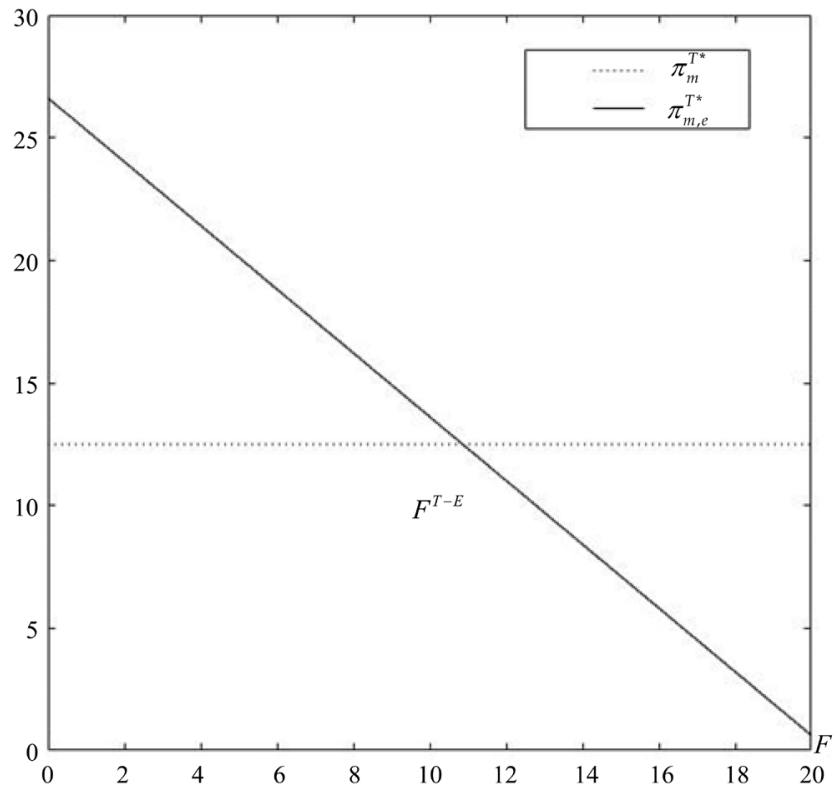

(a)

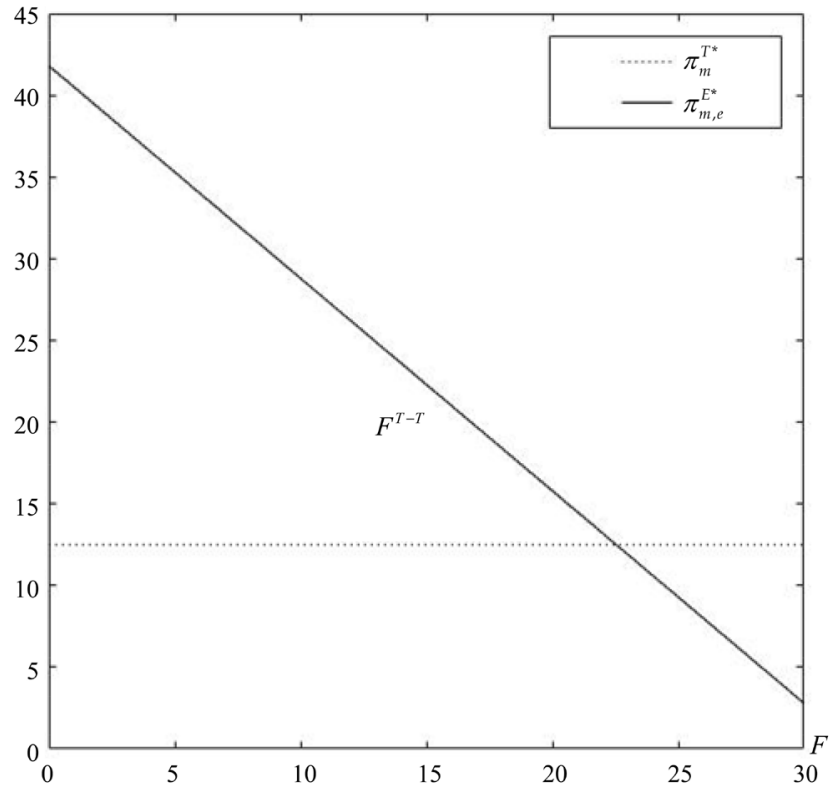

(b)

Figure 2. (a) Relationship between manufacturer profit and channel encroachment cost $\phi \in\left(0, \phi_{e}\right)$; (b) Relationship between manufacturer profit and channel encroachment cost $\phi \in\left(\phi_{e}, 1\right)$. 
In addition, suppose that $r_{f}=0.3$, we can calculate that $\phi_{e}=0.6297$. Figure 3 shows the impact of equity financing ratio and channel establishing cost on the decision-making equilibrium of both parties. As Figure 3 shows that when $\phi \in\left(0, \phi_{e}\right)$ and $F \in\left(0, F^{T-E}\right)$, the manufacturer decides to encroach the retail channel, and the retailer adopts the external financing as the financing strategy; When $\phi \in\left(\phi_{e}, 1\right)$ and $F \in\left(0, F^{T-T}\right)$, under this case, the manufacturer decides to encroach the retail channel, while, the retailer adopts the internal financing as the financing strategy; When $\phi \in\left(0, \phi_{e}\right)$ and $F \in\left(F^{T-E},+\infty\right), \phi \in\left(\phi_{e}, 1\right)$ and $F \in\left(F^{T-T},+\infty\right)$, the manufacturer chooses to sell his products only through retail channel, and in the same time, the retailer select external financing as her financing strategy.

What's more, we analyzed the sensitivity of the main influencing factors $\phi_{e}$, $F^{T-T}$ and $F^{T-E}$ to channel competition. From $\phi_{e} / d>0$, the optimal equity financing ratio is positively correlated with the channel competition coefficient. When the channel competition coefficient increases, it is more beneficial for the retailer to choose external financing. According to $F^{T-T} / d>0$ and $F^{T-E} / d>0$, channel competition coefficient $d$ is positively correlated with channel opening cost threshold $F^{T-T}$ and $F^{T-E}$, that is, the greater the channel competition coefficient $d$ is, the more willing the manufacturer is to open up direct channels. As for the reason, channel competition coefficient affects the payoff of the manufacturer, namely: $\partial \pi_{m, e}^{T^{*}} / \partial d<0, \partial \pi_{m, e}^{E^{*}} / \partial d<0$. Therefore, with the increase of channel competitiveness, the manufacturer's income decreases, so the acceptability of channel establishing cost decreases.

\section{Conclusion}

This paper considers a two-echelon supply chain consisting of a manufacturer and a retailer, in which the retailer has financial constraints. The manufacturer decides whether to invade retail channels and establish the direct channel. If so, whether to form double channels to sell products with retail channels. After the decision of the manufacturer's channel intrusion, the retailer decides to adopt either internal financing (trade credit) or external financing (bank, equity hybrid financing). According to the manufacturer's decision of encroachment and the retailer's decision of financing, the model is constructed to obtain the optimal wholesale price, order quantity and profit. Furthermore, the influence of correlation on equilibrium is analyzed. Finally, the accuracy of the decision is proved intuitively by numerical analysis. The research results show that:

1) The ratio of equity financing affects the financing decisions of the retailer. When the manufacturer does not encroach the retail channel, the internal financing is the retailer financing equilibrium within the range of equity financing assumed in this paper; in contrast, if the manufacturer invades the retail channel, meanwhile, when the equity financing ratio is small, external financing is retailer financing equilibrium; when the equity financing ratio is large, internal financing is retailer financing equilibrium. 


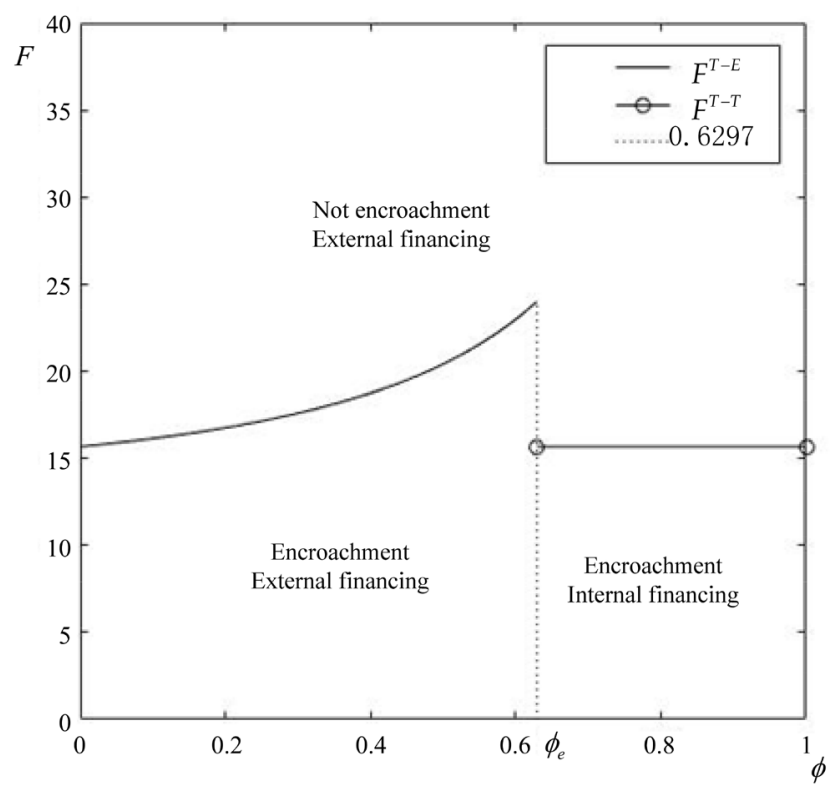

Figure 3. The influence of equity financing ratio and channel establishing threshold on the equilibrium.

2) After the manufacturer decides to establish the direct channel, dual channels is the equilibrium of the manufacturer's channel choice; that is, the revenue of dual channels is always greater than that of the direct channel only.

3) The cost of channel development affects the decision of channel development of manufacturers. When the cost of channel is less than the threshold, the direct channel will be equilibrium for the manufacturer. When the cost of channel development is greater than the threshold, the balance of channel development should be established for the manufacturer without direct channel development.

4) The channel competition coefficient affects the channel development cost threshold, which in turn affects the manufacturer's channel development decision. The channel competition coefficient is negatively correlated with the channel development cost threshold. Therefore, the smaller the channel competition coefficient, the more willing manufacturers are to open up direct sales channels.

Based on the existing results, this paper studies the channel intrusion of manufacturers and the financing decision of retailers in the supply chain with capital constraints, which has guiding significance for the management of the supply chain with capital constraints.

However, this paper only studied the influence of the retailer's capital constraint on the manufacturer's channel encroachment, and lacks the discussion on the influence of the manufacturer's encroachment on the financing strategy of the retailer. In addition, this article only studied the situation where the manufacturer is the leader of the Stackelberg game. It can also study the situation where the retailer is the leader of the Stackelberg game or the Nash game be- 
tween the manufacturer and the retailer. In addition, this article studies deterministic market demand, and can also study uncertain markets or information asymmetry between retailers and manufacturers.

\section{Conflicts of Interest}

The authors declare no conflicts of interest regarding the publication of this paper.

\section{References}

Chen, X. F. (2015). A Model of Trade Credit in a Capital-Constrained Distribution Channel. International Journal of Production Economics, 159, 347-357. https://doi.org/10.1016/j.ijpe.2014.05.001

Daniel, S., Ralt, W. S., \& Margarita, P. S. (2013). A Review of Trade Credit Literature: Opportunities for Research in Operations? European Journal of Operational Research, 231, 245-256. https://doi.org/10.1016/j.ejor.2013.03.016

Duan, L. L., \& Jiao, C. X. (2019). Analysis on the Development of E-Commerce in the New Era. The Farmers Consultant, 21, 148-149.

Fan, X. J., \& Liu, Y. (2016). Manufacturers Introduce the Dual-Channel Price and Service Competition Strategy of Online Channels. Chinese Journal of Management Science, 24, 143-148.

Guo, J. S., Zhou, Y. W., \& Ji, K. (2017a). Dual-Channel Supply Chain Decision with a Risk-Averse Retailer under the Capital Constraint. Operations Research and Management Science, 26, 28-36.

Guo, J. S., Zhou, Y. W., \& Zhong, Y. G. (2017b). The Selection of Trade Credit and Advance Booking Discount Contract for Dual Channel Manufacturer with the Retailer's Capital Constraint. Systems Engineering-Theory \& Practice, 37, 1254-1264.

Li, G., Wu, H. M., \& Xiao, S. (2019). Financing Strategies for a Capital-Constrained Manufacturer in a Dual-Channel Supply Chain. International Transactions in Operational Research, 27, 2317-2339.

Li, Z. X., Gilbert, S. M., \& Lai, G. M. (2014a). Supplier Encroachment as an Enhancement or a Hindrance to Nonlinear Pricing. Production and Operations Management, 24, 89-109. https://doi.org/10.1111/poms.12210

Li, Z. X., Gilbert, S. M., \& Lai, G. M. (2014b). Supplier Encroachment under Asymmetric Information. Management Science, 60, 449-462. https://doi.org/10.1287/mnsc.2013.1780

Matsui, K. (2017). When Should a Manufacturer Set Its Direct Price and Wholesale Price in Dual-Channel Supply Chains? European Journal of Operational Research, 258, 501-511. https://doi.org/10.1016/j.ejor.2016.08.048

Peura, H., Yang, S. A., \& Lai, G. M. (2017). Trade Credit in Competition: A Horizontal Benefit. Manufacturing \& Service Operations Management, 19, 263-289. https://doi.org/10.1287/msom.2016.0608

Wang, C. F., Fan, X. J., \& Yin, Z. (2019). Financing Online Retailers: Bank vs. Electronic Business Platform, Equilibrium, and Coordinating Strategy. European Journal of Operational Research, 276, 343-356. https://doi.org/10.1016/j.ejor.2019.01.009

Xia, J., \& Niu, W. J. (2019). Adding Clicks to Bricks: An Analysis of Supplier Encroachment under Service Spillovers. Electronic Commerce Research and Applications, 37, 
Article ID: 100876. https://doi.org/10.1016/j.elerap.2019.100876

Xiao, X., \& Luo, J. W. (2016). Financing Strategies for Capital Constrained Manufacture in the Dual-Channel Supply Chain. Journal of System \& Manufacture, 25, 121-128.

Yan, R. Z., Li, R. et al. (2019). Study on the Retailer Ordering Strategy in the Perspective of Supply Chain Financing Structure. China Management Science, 27, 451-458.

Yang, H. L., Zhuo, W. Y., \& Shao, L. S. (2017). Equilibrium Evolution in a Two-Echelon Supply Chain with Financially Constrained Retailers: The Impact of Equity Financing. International Journal of Production Economics, 185, 139-149.

https://doi.org/10.1016/j.ijpe.2016.12.027

Yang, H. X., Luo, J. W., \& Zhang, Q. H. (2018). Supplier Encroachment under Nonlinear Pricing with Imperfect Substitutes: Bargaining Power versus Revenue-Sharing. European Journal of Operational Research, 267, 1089-1101. https://doi.org/10.1016/j.ejor.2017.12.027

Yoon, D. H. (2016). Supplier Encroachment and Investment Spillovers. Production and Operations Management, 25, 1839-1854. https://doi.org/10.1111/poms.12580

Zhang, X. J., \& Wang, Y. (2014). Dual-Channel Supply Chain Decision with Retailer's Capital Constraint. Control and Decision, 29, 299-306. 